\title{
Sistema público de escrituração digital (SPED): como as principais universidades da grande Florianópolis estão preparando os acadêmicos para a era digital da contabilidade?
}

\section{Public digital bookkeeping system (SPED): as the main universities are great Florianópolis preparing the academic for the digital age of accounting?}

\author{
Kleber Martins \\ Centro Universitário Municipal de São José - USJ \\ Brasil \\ Bacharel em Ciências Contábeis pelo Centro Universitário Municipal de São José - USJ \\ Scheyla Schlemper \\ Centro Universitário Municipal de São José - USJ \\ Brasil \\ Graduanda em Ciências Contábeis pelo Centro Universitário Municipal de São José - USJ \\ Tamiris Cristina Schutz \\ Centro Universitário Municipal de São José - USJ \\ Brasil \\ Bacharel em Ciências Contábeis pelo Centro Universitário Municipal de São José - USJ
}

\begin{abstract}
Alfredo Lohn Braun
Centro Universitário Municipal de São José - USJ

Brasil

Mestre em Administração pela Universidade do Vale do Itajai - UNIVALI

Data de submissão: 23/10/2016

Data de aceite: $21 / 08 / 2018$
\end{abstract}

\section{Resumo}

O Sistema Público de Escrituração Digital (SPED) representa uma inovação digital no campo da contabilidade, cujo objetivo é de informatizar a relação entre fisco e os contribuintes, através da integração das informações das administrações tributárias federal, estadual e municipal, ou seja, a modernização do cumprimento das obrigações acessórias. Também apresenta o processo de conversão as normas internacionais de contabilidade, que trouxe grandes mudanças nos aspectos legais, operacionais e profissionais. Diante do exposto, objetivo deste estudo é identificar, de que forma as principais universidades da Grande Florianópolis estão preparando os acadêmicos para a era digital da contabilidade. A metodologia utilizada foi de natureza básica e descritiva, com uma abordagem quantitativa de análise dos dados, apoiada em uma 
pesquisa bibliográfica, com o intuito de fundamentar o tema abordado. Os resultados obtidos demonstram que mesmo com a maior parte das universidades da Grande Florianópolis terem alguma disciplina que envolva a contabilidade digital, ainda é deficitário o investimento nesta área, visto que na contabilidade comercial, todas as obrigações acessórias estão convergindo para meios digitais.

Palavras- chave: Contabilidade digital. Sistema Público de Escrituração Digital (SPED). Obrigações acessórias.

\begin{abstract}
The Public Digital Bookkeeping System, is a digital innovation in the field of accounting, whose purpose is to computerize the relationship between tax authorities and taxpayers, through the integration of information in tax federal government, state and local, that is, the modernization the compliance of ancillary obligations. It also presents the process of conversion to international accounting standards, which brought major changes in the legal, operational and professional. Given the above, aim of this study is to identify how the leading universities in Florianópolis are preparing students for the digital accounting was. The methodology used was basic and descriptive with a quantitative approach to data analysis, based on a literature search, in order to support the theme addressed. The results show that even with most of Florianópolis universities have some discipline involving the digital accounting, is still loss-making investment in this area, as in business accounting, all ancillary obligations are converging on digital media.
\end{abstract}

Keywords: Digital Accounting. Public Digital Bookkeeping System (SPED). Accessory obligations.

\title{
1 INTRODUÇÃO
}

Com os avanços tecnológicos, houve a necessidade de um melhor controle e fiscalização, objetivando aumentar a confiança nas operações realizadas pelas empresas. Ainda assim, com este avanço, as empresas continuavam sem uma fiscalização mais abrangente, que evitasse, em primeiro momento, erros na construção das informações, a sonegação e outros crimes tributários. Neste contexto concebeu-se o Sistema Público de Escrituração Digital SPED.

Apesar de a contabilidade ter evoluído lentamente no século passado, ela foi se adaptando com os sistemas mecanizados, principalmente após o surgimento das primeiras máquinas industriais. Nas últimas trinta décadas, o processo manual foi sendo substituído pelo mecânico e logo em seguida pelo eletrônico. Para Druker (2000, p. 1)

[...] após a segunda metade do século XX, um novo cenário é vislumbrado com o advento da informática, quando a tecnologia passou também a ser utilizada no sentido de aumentar a capacidade mental dos recursos humanos segunda metade do século passado, passando a ser compreendido após uma interação entre as diversas áreas do conhecimento, quando o intercâmbio das ciências exatas e humanas se traduziu em benefícios ao processo de inovação. 
No Brasil, o Governo Federal, em 2007, implantou o SPED, que se divide em vários subsistemas, visando proporcionar uma maior interatividade e agilidade no processo de transmissão das informações aos órgãos competentes.

No Decreto $n^{\circ}$. 6.022/07 que o implementou, descreve que:

Art. $2^{\circ} \mathrm{O}$ SPED é instrumento que unifica as atividades de recepção, validação, armazenamento e autenticação de livros e documentos que integram a escrituração comercial e fiscal dos empresários e das sociedades empresárias, mediante fluxo único, computadorizado, de informações.

Com esse panorama, a contabilidade adaptou-se à era digital, exigindo de seus profissionais, maior interação com os profissionais de tecnologia da informação(TI), onde além de contabilizar, o profissional precisa estar familiarizado com as ferramentas tecnológicas, afim de efetuar a entrega, conferencia e análise dos dados que compõe as obrigações assessórias das empresas.

Diante do exposto esta pesquisa tem como proposito responder a seguinte pergunta da pesquisa: De que forma as principais universidades da Grande Florianópolis estão preparando os acadêmicos para a era digital da contabilidade?

Considerando o contexto para o exercício da profissão, o presente trabalho tem a perspectiva de identificar, tomando por amostra as ementas dos cursos de Ciências Contábeis das principais universidades da Grande Florianópolis, como as disciplinas contidas nas grades dos cursos contemplam estas áreas de tecnologia e inovação.

Com a finalidade de alcançar o objetivo proposto apresentou-se a fragmentação em três objetivos específicos: a) identificar as principais universidades que ofertam a graduação em Ciências Contábeis; b) analisar as grades dos cursos; c) observar como as instituições de ensino estão preparando os acadêmicos para a era digital da contabilidade.

\section{REVISÃO DE LITERATURA}

Com o objetivo de introduzir o tema abordado, traz-se uma revisão da literatura na área, a fim de familiarizar o leitor, com os objetivos desta pesquisa. A seguir, teremos um breve histórico sobre a história da contabilidade, sobre as obrigações assessórias, e o sistema SPED.

\subsection{A história da contabilidade no Brasil}

A contabilidade no Brasil originou-se na época colônia, formada pela evolução da sociedade e a imposição de controles contábeis para a evolução das primeiras Alfândegas que surgiram em 1530, com intervenção portuguesa. Em 1808 com a chegada da família real, ocorreu uma evolução socioeconômica do Brasil colônia. Com a implantação dos portos, iniciou-se a comercialização de diversos produtos, a fundação do Banco do Brasil e, como consequências desta evolução começou a emissão do papel moeda.

Segundo Reis e Silva (2007), observa-se que na época colonial até o império, o Brasil sofreu algumas influências de Portugal. As medidas que foram criadas na metrópole, posteriormente, eram adotadas na colônia, como por exemplo, a utilização do método das partidas dobradas. A evolução da contabilidade na época estava ligada diretamente a criação das aulas de comércio.

Com o desenvolvimento dos negócios e dos órgãos públicos, surgiu à necessidade de um profissional de contabilidade, e as escriturações destas contas só deviam ser feitas por quem 
estudasse comércio, porém este estudo só foi realmente estruturado após quase cem anos e foi somente em 1902 que foi fundada a escola de prática de comércio, formando profissionais voltados para a área contábil.

Somente em 1946, com a publicação do Decreto-Lei $n^{\circ} 9.295$, foi criado o Conselho Federal de Contabilidade e os Conselhos Regionais de Contabilidade, de acordo com o que preceitua a referida legislação.

Segundo Marion (2008, p. 26):

A contabilidade é um instrumento que fornece o máximo de informações úteis para tomada de decisões dentro e fora da empresa. Ela é muito antiga e sempre existiu para auxiliar as pessoas a tomarem decisões. Com o passar do tempo, o governo começa a utilizar-se dela para arrecadar impostos e a torna obrigatória para maioria das empresas.

A consistência da escrituração contábil é a transparência e qualidade das informações que direciona os contadores aos Princípios da Contabilidade para que ocorra o fato com segurança e agilidade nos processos.

Schmidt (2000), afirma que no Brasil a evolução da contabilidade sempre foi influenciada pela Legislação. O Código Comercial de 1850 foi uma das primeiras amostras da legislação como elemento propulsor de desenvolvimento contábil brasileiro, e foi extinto pelo Novo Código Civil Brasileiro, que estabeleceu a obrigatoriedade da escrituração contábil e da elaboração anual da demonstração do Balanço Geral das empresas comerciais.

Independente da época, sempre houve a necessidade se obter informações úteis, e atualmente, a contabilidade tem um papel de suma importância para o avanço da economia. Manter-se atualizada é imprescindível para o sucesso e sobrevivência das empresas, tendo se tornado uma ciência social esculpida conforme a necessidade do próprio homem.

O desenvolvimento da contabilidade tem ligação direta com a sociedade e suas peculiaridades, do empirismo à revolução da tecnologia da informação e continuará neste procedimento a serviço da sociedade.

Atualmente, a contabilidade aliada à tecnologia da informação, atravessando a fase do papel para a fase de transmissão digital, proporciona uma maior velocidade de envio, segurança, compartilhamento e confiabilidade dos dados, e toda esta modernização, no entanto, era impedida pela falta de padronização das informações solicitadas, uma vez que as várias declarações eram solicitadas em linguagens diversas pelo governo federal, estadual e municipal. (AZEVEDO; MARIANO, 2009).

Portanto, "o grande desafio é processar os dados empresariais gerando informações tributárias e contábeis com a velocidade e a qualidade requeridas pelo fisco; sendo assim, o velho modelo de troca de dados entre empresas e organizações contábeis apresenta sinais claros de obsolescência" (Duarte, 2013).

Neste contexto, estamos em uma era onde acompanhamos a mudança da escrituração contábil para escrituração contábil digital.

\subsection{Obrigações acessórias}

Obrigação é a relação jurídica que estabelece entre um sujeito ativo, que pode exigir de um sujeito passivo uma prestação de caráter patrimonial, em virtude de uma causa que pode ser a vontade da parte ou a vontade da lei.

A obrigação cuja causa é a vontade das partes é a de direito privado. Já a que surge por determinação legal é de direito público. A obrigação 
tributária tem como causa a lei (ex lege). A obrigação tributária nasce com a ocorrência do fato gerador, estabelecendo uma relação jurídica que vincula o sujeito ativo (Estado), que pode exigir do sujeito passivo (particular) uma prestação patrimonial (dinheiro), em virtude da vontade da lei que institui o tributo. (FABRETTI e FABRETTI, 2005, p.81)

Rocha (2009) declara que as obrigações acessórias são dispositivos que contribuem para administração tributária, indispensável para a apuração, fiscalização e arrecadação de tributos. Essas medidas são amparadas por pelo princípio de legalidade, e somente podem ser instituídas ou reguladas por lei.

Então uma obrigação acessória não é necessariamente implicada no pagamento de tributos, e sim um meio de controlar a forma pelo qual foi determinado o montante do tributo e o descumprimento dessa obrigação pode gerar multas.

O SPED moderniza a sistemática atual do cumprimento das obrigações acessórias transmitidas pelos contribuintes às administrações tributárias e aos órgãos fiscalizadores, utilizando-se a certificação digital para fins de assinatura dos documentos eletrônicos, garantindo assim a validade jurídica dos mesmos apenas na sua forma digital. (BRASIL, 2010).

No entendimento de Britz, Santana e Lunkes (2010), os benefícios do SPED são a escusa de arquivos de papel, redução de custos com arquivos físicos, facilidade na entrega de obrigações acessórias, padronização dos dados informados pelos contribuintes dos diferentes estados brasileiros, qualificação da fiscalização por parte das gestões tributárias, além da diminuição de custos para os órgãos governamentais.

Sendo assim, a obrigação acessória representa e caracteriza o dever administrativo, isto é, um meio indicado a fiscalizar a execução da obrigação tributária de exigência do tributo.

\subsection{Sistema Escrituração Digital (SPED)}

A origem do projeto do Sistema Público de Escrituração Digital - SPED proporciona soluções para atender três esferas do Governo Federal, Estadual e Municipal, possibilitando a integração administrativa e uma fiscalização mais eficaz, pois possibilita "[...] maior integração administrativa, padronização e melhor qualidade das informações [...]" (RECEITA FEDERAL, 2015).

Instituído pelo Decreto $\mathrm{n}^{\circ}$ 6.022, de 22 de janeiro de 2007, o SPED participa do Programa de Aceleração do Crescimento do Governo Federal (PAC 2007-2010) e implementou mais um avanço na informatização da conexão entre o fisco e os contribuintes.

O SPED, em conformidade com o Decreto $\mathrm{n}^{\circ}$. 6.022/07 que o implementou:

Art. 2o O SPED é instrumento que unifica as atividades de recepção, validação, armazenamento e autenticação de livros e documentos que integram a escrituração comercial e fiscal dos empresários e das sociedades empresárias, mediante fluxo único, computadorizado, de informações.

Destaca Young (2009) que, com a criação do SPED o Governo tem maior domínio e desenvoltura na fiscalização das informações contábeis e fiscais das empresas por meio de distribuição de arquivos eletrônicos.

Conforme a Receita Federal, o SPED iniciou-se com três subprojetos: Escrituração Contábil Digital - ECD, Escrituração Fiscal Digital - EFD e Nota Fiscal Eletrônica em Ambiente Nacional com os seguintes objetivos: 
- Promover à integração dos fiscos, mediante a padronização e compartilhamento das informações contábeis e fiscais, respeitadas as restrições legais.

- Racionalizar e uniformizar as obrigações acessórias para os contribuintes, com o estabelecimento de transmissão única de distintas obrigações acessórias de diferentes órgãos fiscalizadores.

- Tornar mais célere a identificação de ilícitos tributários, com a melhoria do controle dos processos, a rapidez no acesso às informações e a fiscalização mais efetiva das operações com o cruzamento de dados e auditoria eletrônica. (Receita Federal, 2016)

Desta forma, o SPED resulta em uma solução tecnológica, substituindo os desempenhos mecânicos, oficializando os arquivos digitais dentro de um modelo específico, com a finalidade de reduzir a complexidade. O SPED revolucionou a sistemática no desempenho das obrigações acessórias pelos contribuintes às administrações tributárias e aos órgãos competentes.

\subsubsection{Módulos do Sistema SPED}

Segundo o Portal do SPED(2016), no sítio da Receita Federal do Brasil, o Sistema SPED, atualmente é dividido em 12 módulos distintos, com funções específicas para os fins que se destinam, como segue abaixo:

Figura 1: Estrutura do SPED

\section{Sistema Público de Escrituração Digital}

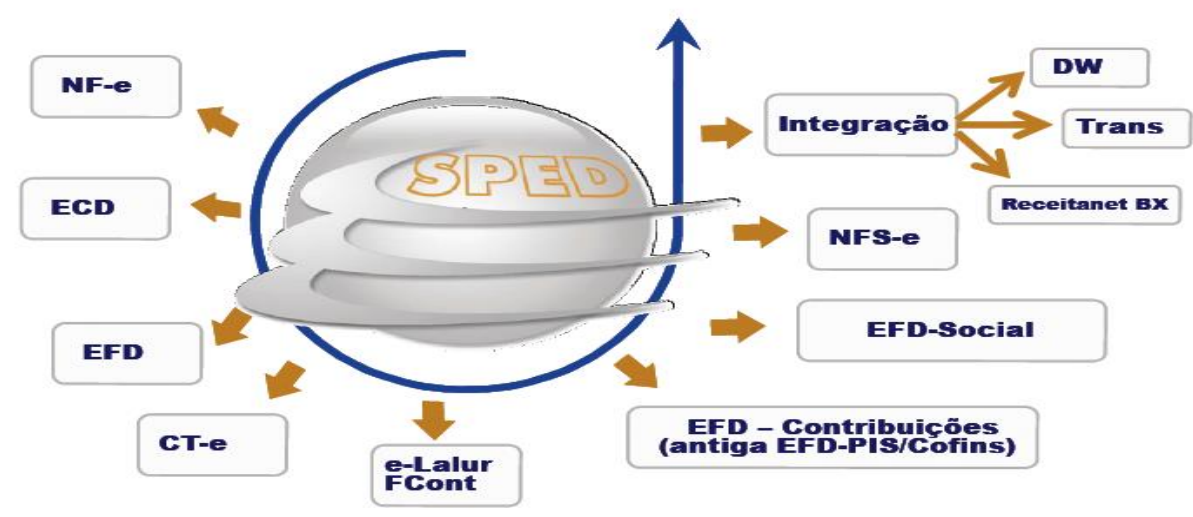

Fonte: Receita Federal do Brasil. (2016)

\section{a. CT-e}

Podemos conceituar o CT-e como um documento de existência exclusivamente digital, emitido e armazenado eletronicamente, com o intuito de documentar uma prestação de serviços de transportes, cuja validade jurídica é garantida pela assinatura digital do emitente e a Autorização de Uso fornecida pela administração tributária do domicílio do contribuinte.

O CT-e poderá ser utilizado para substituir um dos seguintes documentos fiscais:

- Conhecimento de Transporte Rodoviário de Cargas, modelo 8;

- Conhecimento de Transporte Aquaviário de Cargas, modelo 9;

- Conhecimento Aéreo, modelo 10;

- Conhecimento de Transporte Ferroviário de Cargas, modelo 11; 
- Nota Fiscal de Serviço de Transporte Ferroviário de Cargas, modelo 27;

- Nota Fiscal de Serviço de Transporte, modelo 7, quando utilizada em transporte de cargas.

\section{b. ECD}

A Escrituração Contábil Digital (ECD) é parte integrante do projeto SPED e tem por objetivo a substituição da escrituração em papel pela escrituração transmitida via arquivo, ou seja, corresponde à obrigação de transmitir, em versão digital, os seguintes livros:

- I - Livro Diário e seus auxiliares, se houver;

- II - Livro Razão e seus auxiliares, se houver;

- III - Livro Balancetes Diários, Balanços e fichas de lançamento comprobatórias dos assentamentos neles transcritos.

\section{c. ECF}

A Escrituração Contábil Fiscal (ECF) substitui a Declaração de Informações EconômicoFiscais da Pessoa Jurídica (DIPJ), a partir do ano-calendário 2014, com entrega prevista para o último dia útil do mês de junho do ano posterior ao do período da escrituração no ambiente do Sistema Público de Escrituração Digital (Sped). Portanto, a DIPJ está extinta a partir do anocalendário 2014.

\section{d. EFD Contribuições}

A EFD-Contribuições trata de arquivo digital instituído no Sistema Publico de Escrituração Digital - SPED, a ser utilizado pelas pessoas jurídicas de direito privado na escrituração da Contribuição para o PIS/Pasep e da Cofins, nos regimes de apuração não-cumulativo e/ou cumulativo, com base no conjunto de documentos e operações representativos das receitas auferidas, bem como dos custos, despesas, encargos e aquisições geradores de créditos da não cumulatividade.

\section{e. EFD ICMS IPI}

A Escrituração Fiscal Digital - EFD é um arquivo digital, que se constitui de um conjunto de escriturações de documentos fiscais e de outras informações de interesse dos Fiscos das unidades federadas e da Secretaria da Receita Federal do Brasil, bem como de registros de apuração de impostos referentes às operações e prestações praticadas pelo contribuinte em relação ao ICMS e o IPI.

\section{f. EFD Reinf}

A Escrituração Fiscal Digital das Retenções e Informações da Contribuição Previdenciária Substituída (EFD-Reinf) é o mais recente módulo do Sistema Público de Escrituração Digital (SPED) e está sendo construída em complemento ao Sistema de Escrituração Digital das Obrigações Fiscais, Previdenciárias e Trabalhistas (eSocial).

A EFD-Reinf abarca todas as retenções do contribuinte sem relação com o trabalho, bem como as informações sobre a receita bruta para a apuração das contribuições previdenciárias substituídas. A nova escrituração substituirá as informações contidas em outras obrigações acessórias, tais como o módulo da EFD-Contribuições que apura a Contribuição Previdenciária sobre a Receita Bruta (CPRB). 


\section{g. E-financeira}

A e-Financeira é um conjunto de arquivos digitais referentes a cadastro, abertura, fechamento e auxiliares, e pelo módulo de operações financeiras.

Foi instituída pela Instrução Normativa RFB no 1571, de 02 de julho de 2015 que disciplina a obrigatoriedade de prestação de informações relativas às operações financeiras de interesse da Secretaria da Receita Federal do Brasil (RFB).

\section{h. E-social}

O e-Social é um projeto do governo federal e um instrumento de unificação da prestação das informações referentes à escrituração das obrigações fiscais, previdenciárias e trabalhistas e tem por finalidade padronizar sua transmissão, validação, armazenamento e distribuição, constituindo um ambiente nacional.

\section{i. MDF-e}

Manifesto Eletrônico de Documentos Fiscais (MDF-e) é o documento emitido e armazenado eletronicamente, de existência apenas digital, para vincular os documentos fiscais transportados na unidade de carga utilizada, cuja validade jurídica é garantida pela assinatura digital do emitente e autorização de uso pelo Ambiente Autorizador.

\section{j. NFC-e}

A Nota Fiscal de Consumidor Eletrônica - NFC-e - é um documento de existência apenas digital, emitido e armazenado eletronicamente, com o intuito de documentar as operações comerciais de venda presencial ou venda para entrega em domicílio a consumidor final (pessoa física ou jurídica) em operação interna e sem geração de crédito de ICMS ao adquirente.

A NFC-e substitui a nota fiscal de venda ao consumidor, modelo 2, e o cupom fiscal emitido por ECF. Portanto é utilizada na venda a consumidor final.

\section{k. NF-e}

O Projeto NF-e teve como objetivo a implantação de um modelo nacional de documento fiscal eletrônico, identificado pelo modelo 55, visando a substituir a sistemática de emissão do documento fiscal em papel, modelos 1 e 1A, com validade jurídica garantida pela assinatura digital do emitente, simplificando as obrigações acessórias dos contribuintes e permitindo, ao mesmo tempo, o acompanhamento em tempo real das operações comerciais pelo Fisco. $O$ final do processo de implantação das diversas obrigatoriedades de uso da NF-e com alcance nacional, em dezembro de 2010, marcou o fim do Projeto, e a NF-e assumiu o status de um sistema nacional de documento fiscal eletrônico, compartilhado entre as unidades da Federação e a Receita Federal do Brasil.

\section{NFS-e}

O Projeto Nota Fiscal de Serviços Eletrônica (NFS-e) está sendo desenvolvido de forma integrada, pela Receita Federal do Brasil (RFB) e Associação Brasileira das Secretarias de 
Finanças das Capitais (ABRASF), atendendo o Protocolo de Cooperação ENAT n ${ }^{\circ}$ 02, de 7 de dezembro de 2007, que atribuiu a coordenação e a responsabilidade pelo desenvolvimento e implantação do Projeto da NFS-e.

A Nota Fiscal de Serviços Eletrônica (NFS-e) é um documento de existência digital, gerado e armazenado eletronicamente em Ambiente Nacional pela RFB, pela prefeitura ou por outra entidade conveniada, para documentar as operações de prestação de serviços.

\section{METODOLOGIA}

Neste capítulo, busca-se demostrar as técnicas metodológicas aplicadas para o desenvolvimento do estudo.

Para atingir os objetivos do estudo, utilizou-se uma pesquisa de natureza básica e descritiva, com abordagem quantitativa, apoiada em uma pesquisa bibliográfica. Para Moresi(2003, p.8), "pesquisa básica, objetiva gerar conhecimentos novos úteis para o avanço da ciência sem aplicação prática prevista. Envolve verdades e interesses universais".

Quanto a sua abordagem a pesquisa é classificada como quantitativa que segundo Dalfovo, Lana e Silveira (2008, p. 6), "tudo que pode ser mensurado em números, classificado e analisado. utiliza-se de técnicas estatísticas.".

A pesquisa se classifica como descritiva, por discorrer acerca dos conteúdos das disciplinas ministradas nos cursos de contabilidade, nas instituições de ensino da grande Florianópolis, relacionadas à temática contabilidade digital.

Para Gil (2008, p. 46), esse tipo de pesquisa tem como objetivo "[...] a descrição das características de determinada população ou fenômeno ou o estabelecimento de ralações entre variáveis".

Nos procedimentos, utilizou-se o método de pesquisa bibliográfica, ou seja, responder o objetivo com base em relatórios técnicos, demonstrando a opinião de vários autores, livros, dissertações e internet.

A pesquisa bibliográfica é desenvolvida a partir de material já elaborado, constituído principalmente de livros e artigos científicos. Embora em quase todos os estudos seja exigido algum tipo de trabalho desta natureza, há pesquisas desenvolvidas exclusivamente a partir de fontes bibliográficas. (GIL, 2008, p.65)

A coleta de dados foi realizada por meio de uma pesquisa documental nas grades curriculares e ementas dos cursos de Ciências Contábeis das principais universidades da Grande Florianópolis.

A seguir, resumidamente, serão apresentadas as principais instituições de ensino, que ofertam o curso de Ciências Contábeis na região da Grande Florianópolis, informações estas retiradas diretamente do site de cada instituição.

Tabela 01: Universidades Estudadas

\begin{tabular}{ccc}
\hline Instituição & Natureza & Modalidade \\
\hline UFSC - & & \\
Universidade & Publica/Federal & Presencial/EAD \\
$\begin{array}{c}\text { Federal de Santa } \\
\text { Catarina }\end{array}$ & \\
USJ- Centro & \\
Universitário de & Publica/Municipal & Presencial \\
São José & & \\
\hline
\end{tabular}




\begin{tabular}{ccc}
\hline UNIVALI - & & \\
Universidade do & Particular/comunitária & Presencial/EAD \\
Vale do Itajaí & & \\
UNISUL - & & \\
Universidade do Sul & Particular/comunitária & Presencial/EAD \\
de Santa Catarina & & \\
ESTÁCIO - & Particular/privada & Presencial/EAD \\
Universidade & & \\
Estácio de Sá & & \\
ANHANGUERA - & Particular/privada & Presencial/EAD \\
Faculdade & & \\
Anhanguera & & \\
UNISOCIESC - & & \\
Universidade & Particular/privada & Presencial/EAD \\
Sociedade & & \\
Educacional de & & \\
Santa Catarina & & \\
FBM -Faculdade & Particular/privada & Presencial \\
Borges de & & \\
Mendonça & & \\
UNIASSELVI - & Particular/privada & Presencial/EAD \\
Centro & & \\
Universitário & & \\
Leonardo Da Vinci & & \\
IES - Instituto de & & \\
Ensino Superior da & Particular/privada & Presencial/EAD \\
Grande & & \\
Florianópolis & & \\
\hline Pelos autes. & & \\
\hline
\end{tabular}

Elaborado pelos autores.

\subsection{Identificação das disciplinas de voltadas para a contabilidade digital}

Após análise da grade curricular das 10 principais universidades que ofertam a graduação em Ciências Contábeis na Grande Florianópolis, foi elaborado o quadro a seguir:

Quadro 01: Identificação das disciplinas de contabilidade digital

\begin{tabular}{|c|c|c|c|}
\hline Instituição & $\begin{array}{c}\text { Modalidade da } \\
\text { Graduação em } \\
\text { Ciências } \\
\text { Contábeis }\end{array}$ & $\begin{array}{c}\text { Possui } \\
\text { Disciplina que } \\
\text { envolva } \\
\text { contabilidade } \\
\text { digital? }\end{array}$ & $\begin{array}{c}\text { Quantas } \\
\text { Disciplinas } \\
\text { que envolvem } \\
\text { contabilidade } \\
\text { digital? }\end{array}$ \\
\hline UFSC & Presencial & Sim & 2 \\
\hline USJ & Presencial & Sim & 1 \\
\hline UNIVALI & Presencial & Sim & 1 \\
\hline UNISUL & Presencial/EAD & Sim & 2 \\
\hline ESTÁCIO & Presencial & Sim & 2 \\
\hline ANHANGUERA & Presencial/EAD & Sim & 1 \\
\hline UNISOCIESC & Presencial & Sim & 1 \\
\hline BORGES DE & Presencial & Sim & 1 \\
\hline MENDONÇA & & Sim & 3 \\
\hline UNIASSELVI & Presencial/EAD & &
\end{tabular}


MARTINS, K. et al. Sistema público de escrituração digital (SPED): como as principais universidades da grande Florianópolis estão preparando os acadêmicos para a era digital da contabilidade? Revista Unemat de

Contabilidade, v. 7, n. 13, p. 22-36, 2018.

\begin{tabular}{|c|c|c|c|}
\hline IES & Presencial/EAD & Não & 0 \\
\hline
\end{tabular}

Fonte: Elaborado pelos autores.

Analisando a grade curricular, e as ementas de cada curso, constatou-se que $90 \%$ das graduações em Ciências Contábeis, possuem alguma disciplina relacionada ao tema contabilidade digital, apresentando em sua ementa, elementos relacionados ao conhecimento para a elaboração de contabilidade por meios digitais, atendendo de alguma forma às necessidades das obrigações acessórias do SPED como pode ser demonstrado abaixo:

Quadro 02: Identificação das ementas.

\begin{tabular}{|c|c|c|}
\hline Instituição & Disciplina & Ementa \\
\hline \multirow[t]{2}{*}{ UFSC } & $\begin{array}{c}\text { Laboratório de Prática } \\
\text { Contábil }\end{array}$ & Práticas Contábeis em Laboratório. \\
\hline & $\begin{array}{c}\text { Sistemas de } \\
\text { Informação Contábil }\end{array}$ & Práticas com sistemas contábeis. \\
\hline USJ & $\begin{array}{l}\text { Contabilidade } \mathrm{V}- \\
\text { Laboratório Contábil }\end{array}$ & $\begin{array}{c}\text { Lançamentos contábeis/fiscais/folha } \\
\text { de pagamento; Demonstrações } \\
\text { contábeis; Notas explicativas. }\end{array}$ \\
\hline UNIVALI & $\begin{array}{l}\text { Sistemas de } \\
\text { Informações } \\
\text { Gerenciais }\end{array}$ & $\begin{array}{l}\text { Sistemas de informações gerenciais; } \\
\text { Sistemas de custeio. }\end{array}$ \\
\hline \multirow[t]{2}{*}{ UNISUL } & $\begin{array}{l}\text { Contabilidade } \\
\text { Financeira e } \\
\text { Patrimonial } \\
\end{array}$ & $\begin{array}{c}\text { Contabilidade Comercial: Operações } \\
\text { Avançadas, Operações Comerciais; } \\
\text { Escritório de Práticas da } \\
\text { Contabilidade Financeira. }\end{array}$ \\
\hline & Controladoria & $\begin{array}{c}\text { Contabilidade Estratégica; Escritório } \\
\text { de Práticas da Contabilidade } \\
\text { Gerencia } \\
\end{array}$ \\
\hline \multirow[t]{2}{*}{ ESTÁCIO } & $\begin{array}{l}\text { Prática Contábil } \\
\text { Informatizada I }\end{array}$ & Práticas contábeis informatizadas. \\
\hline & $\begin{array}{l}\text { Prática Contábil } \\
\text { Informatizada II }\end{array}$ & Práticas contábeis informatizadas. \\
\hline ANHANGUERA & $\begin{array}{l}\text { Laboratório de Gestão } \\
\text { Contábil }\end{array}$ & $\begin{array}{l}\text { Plano de contas; Controles Internos; } \\
\text { Lançamentos contábeis; Impostos; } \\
\text { Folha de Pagamento; Livros Fiscais; } \\
\text { Encerramentos das Contas e } \\
\text { Apuração dos Resultados; Análise } \\
\text { das demonstrações contábeis; } \\
\text { Utilização de software de } \\
\text { contabilidade para a disciplina. }\end{array}$ \\
\hline UNISOCIESC & $\begin{array}{l}\text { Sistemas Contábeis } \\
\text { em Laboratório }\end{array}$ & $\begin{array}{l}\text { Softwares de contabilidade; } \\
\text { Cadastramento de empresas; } \\
\text { Definição do Plano de contas; } \\
\text { Históricos padrões, Centro de custos; } \\
\text { Sistema contábil: lançamentos em } 1^{\text {a }} \text {, } \\
2^{\mathrm{a}}, 3^{\mathrm{a}} \text { e } 4^{\mathrm{a}} \text { fórmulas, conciliação, } \\
\text { balancete de verificação, razão, }\end{array}$ \\
\hline
\end{tabular}




\begin{tabular}{|c|c|c|}
\hline & & $\begin{array}{l}\text { diário, encerramento das contas de } \\
\text { resultado, demonstrações contábeis } \\
\text { (balanço patrimonial e demonstração } \\
\text { do resultado }\end{array}$ \\
\hline $\begin{array}{l}\text { BORGES DE } \\
\text { MENDONÇA }\end{array}$ & $\begin{array}{l}\text { Aplicativos Gerenciais } \\
\text { e Contábeis }\end{array}$ & $\begin{array}{l}\text { Atividades práticas com sistemas } \\
\text { gerenciais e contábeis. }\end{array}$ \\
\hline \multirow{3}{*}{ UNIASSELVI } & $\begin{array}{l}\text { Prática Contábil em } \\
\text { Laboratório I }\end{array}$ & Práticas contábeis informatizadas. \\
\hline & $\begin{array}{l}\text { Prática Contábil em } \\
\text { Laboratório II }\end{array}$ & Práticas contábeis informatizadas. \\
\hline & $\begin{array}{l}\text { Prática Contábil em } \\
\text { Laboratório III }\end{array}$ & Práticas contábeis informatizadas. \\
\hline
\end{tabular}

Fonte: Elaborado pelos autores.

Entre as 10 universidades estudadas, destacam-se duas, UFSC, UNISUL, Estácio e UNIASSELVI, que apresentam duas ou mais disciplinas que envolvam a contabilidade digital, estando assim concatenadas às demandas do mercado e as inovações inerentes a prática da contabilidade comercial.

Um aspecto importante, é que não foi localizada nas ementas, nenhuma informação acerca do uso ou do treinamento voltado para o sistema SPED, que de alguma forma, esta interligado com praticamente todos os setores da contabilidade comercial.

Destaca-se ainda a ausência destas disciplinas em uma das instituições estudadas.

\section{$5 \quad$ Considerações Finais}

Este estudo foi realizado com o objetivo de identificar de que forma as principais Instituições de Ensino Superior da Grande Florianópolis estão preparando os acadêmicos para a era digital da contabilidade. Após analise nas grades curriculares e ementas, foram evidenciadas as disciplinas, que tinham por foco, abordar os temas relacionados às atividades de elaboração da contabilidade digital. Constatou-se que mesmo com $90 \%$ das universidades ofertando alguma disciplina que envolva contabilidade digital, não é possível afirmar que as ementas são capazes de atender os objetivos, visto que as mesmas são amplas e nenhuma é explicita quanto ao tema contabilidade digital, tão pouco o atendimento das obrigações acessórias exigidas no contexto digital.

Destarte podemos afirmar acerca da necessidade de disciplinas mais específicas para o projeto SPED, com função de preparar o acadêmico para o uso destas ferramentas, bem como estimula-los a utiliza-las como ferramenta de auxílio na tomada de decisão e de gestão estratégica dos negócios das empresas clientes, bem como a do próprio escritório.

O Presente estudo obteve uma amostra de 10 universidades que atuam na região da Grande Florianópolis, conseguindo obter de maneira eficiente as informações necessárias diretamente nos sites de cada instituição, e alcançando o objetivo proposto no estudo concretizado.

Como indicações de futuros estudos, sugerem-se pesquisas voltadas para a verificação do alinhamento entre as disciplinas ofertadas pelas instituições e a execução das tarefas, aplicando por meio de questionário dirigido aos egressos das instituições. Indicam-se também estudos referentes ao desenvolvimento de estratégias a partir das exigências do programa de escrituração digital.

\section{REFERÊNCIAS}


ANHANGUERA, FACULDADE ANHANGUERA. Ementa da Graduação em Ciências Contábeis. Disponível

em:

http://cms.anhanguera.com/storage/web_aesa/g_cadastro_apoio/g_curso_graduacao/cienciasc ontabeis.pdf >. Acesso em: 04 out. 2016.

AZEVEDO, Osmar Reis; MARIANO, Paulo Antonio. SPED: Sistema Público de Escrituração Digital. São Paulo: IOB, 2009.

BM, FACULDADE BORGES DE MENDONÇA. Ementa da Graduação em Ciências Contábeis. Disponível em: < http://www.bm.edu.br/wp-content/uploads/2011/07/Matrizcurricular1.pdf >. Acesso em: 04 out. 2016.

BRASIL SPED - Sistema Público de Escrituração Digital. Disponível em: < http://www1.receita.fazendo.gov.br/sistemas/sped-contabil/default.html >. Acesso em: 04 out. 2016.

BRASIL, DECRETO $\mathbf{N}^{\circ}$ 6.022, DE 22 DE JANEIRO DE 2007. Disponível em: < http://www.planalto.gov.br/ccivil_03/_ato2007-2010/2007/Decreto/D6022.htm > Acesso em 07/06/2016.

BRASIL, DECRETO nº 107, de 23 de maio de 2008. Departamento Nacional do Registro do Comércio através da Instrução Normativa Dnrc. Disponível em:< http://sijut.fazenda.gov.br/netacgi/nphbrs?s1=IN000001072008052301\$.CHAT.\%20E\%20DNRC.ORGA.\&l=0\&p=1\&u=/netahtml/ Pesquisa.htm\&r=0\&f=S\&d=SIAT\&SECT1=SIATW3 >. Acesso em: 07/06/2016.

BRASIL, DECRETO nº 787, de 19 de novembro de 2007. Instrução Normativa. Disponível em:<

http://normas.receita.fazenda.gov.br/sijut2consulta/link.action?idAto $=48709 \& v i s a 0=$ anotado >. Acesso em: 07/06/2016.

BRASIL, LEI No 5.172, DE 25 DE OUTUBRO DE 1966. Artigo $n^{\circ} 113$ do Código Tributário Nacional - Disponível em: < http://www.planalto.gov.br/ccivil_03/leis/L5172Compilado.htm $>$. Acesso em: 07/06/2016.

BRASIL, Receita Federal do, SPED. Disponível em: < http://www1.receita.fazenda.cov.br/sistema/spedcontabil/default.htm $>$ Acesso em 30 Abr. 2016.

BRASIL. Receita Federal do Brasil. In: Sistema Público de Escrituração Digital. Disponível em: < http://www1.receita.fazenda.gov.br/Sped/ >. Acesso em: 27 mar. 2016.

BRITZ, C.M; SANTANA, A.F.B; LUNKES, C.A. Sistema Público de Escrituração Digital: percepção dos gestores das cooperativas agropecuárias catarinenses sobre os prováveis benefícios produzidos com a sua implantação. ABCustos: Revista da Associação Brasileira de Custos. v. 5, n.3, set./dez. 2010. Disponível em: < www.unisinos.br/abcustos/_pdf/187.pdf > Acesso em: 20 fev. 2016. 
DALFOVO, Michael Samir; LANA, Rogério Adilson; SILVEIRA, Amélia. Métodos quantitativos e qualitativos: um resgate teórico. Revista Interdisciplinar Científica Aplicada, Blumenau, v.2, n.4, p.01- 13, Sem II. 2008

DRUCKER, Peter. Além da revolução da informação. HSM Management. São Paulo: Savana, ano 3, n. 18, janeiro-feveireiro 2000.

DUARTE, roberto dias. Contabilidade: novo empreendedorismo. 2013. Disponível em < http://www.robertodiasduarte.com.br/ > . Acesso em 12 jun. 2016.

ESTÁCIO, UNIVERSIDADE ESTÁCIO DE SÁ. Ementa da Graduação em Ciências Contábeis. Disponível em: < http://portal.estacio.br/graduacao/ciencias-contabeis >. Acesso em: 04 out. 2016.

FABRETTI, Láudio Camargo. Legislação Tributária. 9 ed. São Paulo: Editora Atlas, 2005.

GIL, Antonio Carlos. Como elaborar projetos de pesquisa. 4. ed. São Paulo: Atlas, 2008.

IES, INSTITUTO DE ENSINO SUPERIOR DA GRANDE FLORIANÓPOLIS. Ementa da Graduação em Ciências Contábeis. Disponível em: < http://www.ies.edu.br/ensino/graduacao/tradicionais/ciencias_contabeis.asp $>$. Acesso em: 04 out. 2016.

MARION, José Carlos. Contabilidade básica. 8.ed. São Paulo: Atlas, 2008.

MORESI, Eduardo. Metodologia da Pesquisa. Brasília: O Autor, 2013.

REIS, A. de J.; SILVA, S. L. A história da contabilidade no Brasil. Disponível em: < http://www.revistas.unifacs.br/index.php/sepa/article/view/299 >. Acesso em: 20 jun. 2016

ROCHA, Juliana Ferreira Pinto. As obrigações acessórias e as sansões políticas. Revista Diálogo e Interação - FACCREI/ FACED, Cornélio Procópio, v. 2, 2009. 13 p. Disponível em: $<$ http://www.faccrei.edu.br/dialogoeinteracao/ > Acesso em: 20 jun. 2016.

SCHMIDT, Paulo. História do pensamento contábil. São Paulo: Bookman, 2000.

UFSC, UNIVERSIDADE FEDERAL DE SANTA CATARINA. Ementa da Graduação em Ciências Contábeis. Disponível em: < http://cagr.sistemas.ufsc.br/relatorios/curriculoCurso?curso=317 >. Acesso em: 04 out. 2016.

UNIASSELVI, CENTRO UNIVERSITÁRIO LEONARDO DA VINCI. Ementa da Graduação em Ciências Contábeis. Disponível em: < http://www.grupouniasselvi.com.br/Paginas/Detalhes-do-

Curso.aspx?CD=163\&Curso=CiEncias\%20ContAbeis >. Acesso em: 04 out. 2016.

UNISOCIESC, UNIVERSIDADE SOCIEDADE EDUCACIONAL DE SANTA CATARINA. Ementa da Graduação em Ciências Contábeis. Disponível em: < http://unisociesc.org.br/pt/cursosgraduacao $/$ conteudo.php?tipo $=$ curso $\& i d=727 \& m n u=1111 \& \mathrm{crs}=104 \&$ top $=0$ $>$. Acesso em: 04 out. 2016. 
UNISUL, UNIVERSIDADE DO SUL DE SANTA CATARINA. Ementa da Graduação em Ciências Contábeis. Disponível em: https://www.uaberta.unisul.br/repositorio/download/web/portal/manuais_de_cursos/manual_g rad_ciencias_contabeis.pdf $>$. Acesso em: 04 out. 2016.

UNIVALI, UNIVERSIDADE DO VALE DO ITAJAI. Ementa da Graduação em Ciências Contábeis. Disponível em: < http://www.univali.br/ensino/graduacao/ceciesagestao/cursos/ciencias-contabeis/ciencias-contabeis-biguacu/matrizcurricular/Paginas/Default.aspx >. Acesso em: 04 out. 2016.

USJ, CENTRO UNIVERSITARIO MUNICIPAL DE SÃO JOSÉ. Ementa da Graduação em Ciências Contábeis. Disponível em: < http://usj.edu.br/wpcontent/uploads/2014/07/Doc01_EMENTARIO_CURRICULAR_DO_CCO_2015.pdf $>$. Acesso em: 04 out. 2016.

YOUNG, L. H. B. SPED: Sistema Público de Escrituração Digital. Curitiba: Juruá,2009. 